Available online on 15.04.2020 at http://jddtonline.info
Open Access to Pharmaceutical and Medical Research
unrestricted non-commercial use, provided the original work is properly cited

Open@ Access

Research Article

\title{
Relation between low birth weight and Maternal blood lead levels in Sidi Bel Abbes, Algeria: a case-control study
}

\author{
Moussaoui Faiza, Demmouche Abbassia* \\ Biotoxicology Laboratory, Department of Biology. Faculty of Naturel Science and life. Djillali Liabes University; Sidi Bel Abbes. Algeria
}

\begin{abstract}
Background: Several epidemiological studies have investigated high lead ( $\mathrm{Pb}$ ) exposure and pregnancy outcomes,but few studies have investigated the association of low lead exposure and low birth weight (LBW). The aims of this study were to estimate the mat ernal blood lead levels (BLL), to identify determinants for BLL among parturient woman and to evaluate the association of maternal BLL andLBW. Methods: From July 2017 to February 2018, we carried out a case control study in the genecology and obstetrics hospital of Sidi Bel Ab bes, Algeria. Lead concentrations in maternal blood samples collected at delivery were measured in 29mother who delivered term LBW cases group and 29 mother who give birth to a term normal weight baby matched controls.Blood lead levels were analyzed by inductively coupled plasma mass spectrometry. Results: Mean maternal BLLwere higher among normal groups than in mothers of LBW, but this difference was not significant $(23,076 \pm 16,120$, versus $18,086 \pm 6,641 \mathrm{ug} / \mathrm{l} \mathrm{p}=0.247)$. Our results indicate that the mean lead level was nothigher in LBW neonates, and the whole blood lead was not related to the birth weight. In addition,there was interaction of daily kohl use and maternal BLL. Conclusion:This study suggeststhat maternal BLL was not significantly associated with LBW. Mothers with daily use of kohl during pre gnancy were more likely to have elevate blood lead concentrations.
\end{abstract}

Keywords: case-control study, low birth weight, Algeria, lead, kohl.

Article Info: Received 18 Feb 2020; Review Completed 22 March 2020; Accepted 04 April 2020; Available online 15 April 2020

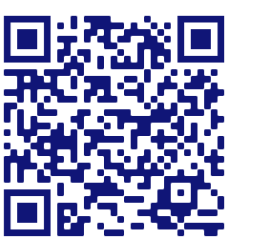

\section{Cite this article as:}

Moussaoui F, Demmouche A, Relation between low birth weight and Maternal blood lead levels in Sidi Bel Abbes, Algeria: a case-control study Journal of Drug Delivery and Therapeutics. 2020; 10(2-s):115-119

http://dx.doi.org/10.22270/jddt.v10i2-s.4023

Pr Abbassia DEMMOUCHE. Professor in Biology, Biotoxicology laboratory, Department of Biology. Faculty of Naturel Science and life. Djillali Liabes University; Sidi Bel Abbes. Algeria

\section{BACKGROUND}

The birth weight of infant is presumably the most critical single factor that influences the future survival and personal satisfaction. It is additionally a significant predictor of post neonatal, baby and childhood morbidity and mortality. Consequently, birth weight has for quite some time been a subject of clinical and epidemiological studies and a territory for public health interest[1]. Various preventable hazard factors have been connected to poor fetal development, including lead exposure during pregnancy $[2,3]$.

Lead $(\mathrm{Pb})$ is a neurotoxic metal that is broad in nature. The expulsion of lead from water funnels, paint and sustenance jars, and a prohibition on lead added substances to petroleum in many nations has lessened introduction to lead as of late, albeit industrial exercises, for example, mining, purifying, lead shot produce and battery make and reusing are still of concern. Sustenance and drink, water, residue and soil stay as imperative wellsprings of introduction, as does cigarette smoking $[4,5]$.
The placental barrier is porous to lead and levels in cord blood were accounted for to achieve 5 to $10 \%$ of the maternal BLL[6,7]. Also lead might be discharged from maternal bone stores among pregnancy and hence may turn into a wellspring ofintoxication for the fetus [6].from 12 weeks of gestation until birth, Lead can be transmitted from the future mother to herfetus through the placenta[8,9].

In spite of the way that the hostile consequences for pregnancy outcomes at elevated lead exposure have been documented for a considerable length of time, there is vulnerability in regards to the effect of presentation to bring low levels ordinarily experienced daily, for example, that because of lead containing cosmetics [6].

Variety studies have recommended that maternal exposure to low lead levels during pregnancy is a negative indicator of birth weight $[10,11]$, length of newborn and head circumference (HC) [10]. In contrast, other studies found no associations between maternal blood lead levels and any birth outcome measures for the same levels. 


\section{METHODS:}

This study was a case-control study conducted in genecology and obstetrics hospital of Sidi Bel Abbes, West of Algeria. Form July 2017 to February 2018, a total of 29 cases and 29 matched controls were incorporated into our examination. Cases were mothers who delivered a live singleton term low birth weight infant (gestational age $\geq 37$ weeks and birth weight $<2500 \mathrm{~g})$. ). Controls were mothers who delivered a live singleton term infant with normal birth weight between $\geq 2500 \mathrm{~g}$ and $<4000 \mathrm{~g}$.

Women with multiple pregnancies, and those who gave birth to apreterm, a dead at birth infant or an infant with a birth weaknesswere excluded. For each case, one control was randomly selected based on the matching variables infant sex. The appropriateness criteria for participants are: a)residence in the study areas at the time of the recruitment period for a period of one year at least. b) absence of illnessessuch as chronic hypertension,renal failure and preeclampsia.

Participants were invited to provide blood sample and participate in a face-to-face interview.The questionnaire elicited on maternal information included sociodemographic factors(maternal age, education, occupation, weight and height), obstetric history and sources of lead exposure; and on newborn characteristics (weight, sex, gestational age, head circumference, Apgar score).

On the day of delivery 4 milliliters of venous blood from 58 pregnant women was placed in a heparinized tube and stored at $-20^{\circ} \mathrm{C}$ prior to analysis. The total leadconcentrations in bloodwere determined by inductively coupled plasma massspectrometry.

The data were analyzed on the Statistical Package for Social Sciences version 23 (SPSS). The general characteristics of cases and controls were presented as a number (\%), and the Pearson chi-square test was used to evaluate the differences in the variables between cases and controls.

We examined the relationship between birth weight, lead levels and known determinants of size at birth using by Mann - Whitney and Kruskal-Wallis tests since the distributions of lead levelswere found to be skewed following the Kolmogorov-Smirnovnormalitytest.

We used bivariate correlation to evaluate the relationship first time between lead levels and newborn parameters then between BLL and the use of kohl in the other hand. The Partial correlation was assessed to eliminate the impact of confounders' variables.

\section{RESULTS:}

The mean maternal age at delivery was $29,05 \pm 5,945$ years with a scope of 19- 44 years and the average Body Mass Index (BMI) was $23.3 \mathrm{~kg} / \mathrm{m}$. There were 22 male newborns and 36 female newborns with mean weight
$2846,81 \pm 611,901 \mathrm{~g}$. General characteristics of the cases and controls are presented in Table 1. Compared to the controls, the case mothers had lower educational attainment (less than high school $69,0 \%$ vs. $41,4 \%$ ) with significant statistical difference. There were higher percentages of case mothers who were underweight $(40,7 \%$ vs. $17,9 \%)$ and more likely to be primiparous (41,4\%vs. $27,6 \%$ ) than controls.

The mean maternal BLL was 20,581 $\pm 12,476 \mathrm{ug} / \mathrm{l}$ with a range of 7,90 to $80,60 \mathrm{ug} / \mathrm{l}$. The controls mothers hadhigher BLL $23,076 \pm 16,120 \mathrm{ug} / \mathrm{l}$ compared to the case mothers $18,086 \pm 6,641 \mathrm{ug} / \mathrm{l}$, but this difference was not significant $(\mathrm{p}<0.247)$.

The correlation between maternal lead concentrations and weight of neonates was analyzed, which showed no significant relationship between these variables.

The correlation between lead levels in maternal blood and headcircumference of newborns, gestational age and Apgar scorewere also assessed, and no significantcorrelation was found between lead concentrations and the newborns' characteristics. Similar results when the correlation was assessed in terms of newborns birth weight categories. Therefore, the correlation between these variables was not significant neither in cases (low birth weight infants) nor in controls (normal birth weight infants) Table 2.

Positive significant relationship was found between birth weight and maternal BLL using the partial correlation witch was assessed by eliminating the effects of maternal age, gestational age, parity, maternal occupation and education statue. (Correlation coefficient, 0,292 and significance level, $0,034)$.

As mentioned in Table 3, Kruskal Willy test analyses revealed that maternal age and prepregnancy BMI categories were not associated neither with blood lead levels nor with newborn's birth weight. Mannwhiteny test showed that education level (less than high school/high school or more), passive smoking (yes/no), parity (primiparous/multiparous), occupation statue (employed/unemployed), as well as gender of newborn and area of residence (urban/rural) were not associated with the tow variables (lead concentrations and birth weight).However, analyses revealed that maternal blood lead levels and newborn's birth weight were higher in the daily user'skohl groupthan in not users of this cosmetic product group, with $\mathrm{p}<0.001$ and $\mathrm{p}<0.020$ respectively.

As shows Table 4, a significant correlation between maternal blood lead levels and use of kohl (cosmetic product) ( $p<0,001)$. Related to infants groups only controls group had a significant association between the two variables. This significant relationship between maternal BLL persisted also after using the partial correlation by eliminating the effects of maternal age, parity, maternal occupation, education statue and BMI (Correlation coefficient, -0,429 and significance level, 0,002). 
Table 1: association between maternal characteristics and low birth weight cases and controls groups.

\begin{tabular}{|c|c|c|c|c|}
\hline \multicolumn{2}{|c|}{ Characteristics } & Case $(\mathrm{N}=29)$ & Control $(\mathrm{N}=29)$ & $P$ value $\left(x^{2}\right)$ \\
\hline \multirow[t]{2}{*}{ Infant sex } & Male & $11(37,9 \%)$ & $11(37,9 \%)$ & \multirow[b]{2}{*}{1} \\
\hline & Female & $18(62,1 \%)$ & $18(62,1 \%)$ & \\
\hline \multirow{3}{*}{ Maternal age(years) } & $<25$ & $06(20,7 \%)$ & $10(34,5 \%)$ & \multirow{3}{*}{0,259} \\
\hline & $25-29$ & $10(34,5 \%)$ & $05(17,2 \%)$ & \\
\hline & $>=30$ & $13(44,8 \%)$ & $14(48,3 \%)$ & \\
\hline \multirow{2}{*}{ Education } & Less than high school & $20(69,0 \%)$ & $12(41,4 \%)$ & \multirow{2}{*}{0,035} \\
\hline & high school or more & $09(31,0 \%)$ & $17(58,6 \%)$ & \\
\hline \multirow{3}{*}{ Pre-pregnancy BMI } & Underweight & $11(40,7 \%)$ & $05(17,9 \%)$ & \multirow{3}{*}{0,056} \\
\hline & Normal & $08(29,6 \%)$ & $06(21,4 \%)$ & \\
\hline & Overweight & $08(29,6 \%)$ & $17(60,7 \%)$ & \\
\hline \multirow[t]{2}{*}{ Parity } & Primiparous & $12(41,4 \%)$ & $08(27,6 \%)$ & \multirow[b]{2}{*}{0,269} \\
\hline & Multiparous & $17(58,6 \%)$ & $21(72,4 \%)$ & \\
\hline \multirow[t]{2}{*}{ Residence } & Urban & $09(31,0 \%)$ & $14(48,3 \%)$ & \multirow[b]{2}{*}{0,180} \\
\hline & Rural & $20(69,0 \%)$ & $15(51,7 \%)$ & \\
\hline \multirow[t]{2}{*}{ Use of kohl } & Yes & $03(10.3 \%)$ & $10(34.5 \%)$ & \multirow{2}{*}{0.028} \\
\hline & Non & $26(89.7 \%)$ & $19(65.5 \%)$ & \\
\hline \multirow[t]{2}{*}{ Occupational status } & Employed & $05(17,2 \%)$ & $03(10,3 \%)$ & \multirow[b]{2}{*}{0,446} \\
\hline & Un-employed & $24(82,8 \%)$ & $26(89,7 \%)$ & \\
\hline
\end{tabular}

Table 2: association between maternal BLL and newborn parameters.

\begin{tabular}{|l|l|l|l|l|c|c|}
\hline & \multicolumn{2}{|l|}{ Total population (n=58) } & \multicolumn{2}{l|}{ Cases LBW (n=29) } & \multicolumn{2}{l|}{ Controls NBW (n=29) } \\
\cline { 2 - 8 } variable & $\begin{array}{l}\text { Correlation } \\
\text { Coefficient }\end{array}$ & Sig & $\begin{array}{l}\text { Correlation } \\
\text { Coefficient }\end{array}$ & Sig & $\begin{array}{l}\text { Correlation } \\
\text { Coefficient }\end{array}$ & Sig \\
\hline Birth weight & 0,164 & 0,218 & 0,085 & 0,663 & 0,026 & 0,893 \\
\hline Head circumference & 0,044 & 0,777 & 0,070 & 0,750 & 0,075 & 0,739 \\
\hline Gestational age & $-0,026$ & 0,847 & $-0,054$ & 0,782 & $-0,266$ & 0,164 \\
\hline $\mathbf{5}$ min Apgar score & 0,176 & 0,187 & 0,327 &, 083 & $-0,027$ & 0,889 \\
\hline
\end{tabular}

\begin{tabular}{|c|c|c|c|c|c|}
\hline \multicolumn{2}{|c|}{ Variables } & \multirow{2}{*}{$\begin{array}{l}\text { Lead level ug/L } \\
21,30 \pm 17,89\end{array}$} & \multirow{3}{*}{$\begin{array}{l}\text { P value } \\
0.320\end{array}$} & \multirow{3}{*}{$\begin{array}{l}\text { Birth weight g } \\
2819,32 \pm 680,19 \\
2863,61 \pm 575,69\end{array}$} & \multirow{3}{*}{$\begin{array}{l}\text { P value } \\
0.987\end{array}$} \\
\hline \multirow[t]{2}{*}{ Infant sex } & male & & & & \\
\hline & female & $20,54 \pm 08,92$ & & & \\
\hline \multirow[t]{3}{*}{ Maternal age(years) } & $<25$ & $17,84 \pm 06,62$ & \multirow[t]{3}{*}{0.545} & $3043,44 \pm 515,21$ & \multirow[t]{3}{*}{0.108} \\
\hline & $25-29$ & $22,99 \pm 15,8$ & & $2657,33 \pm 491,29$ & \\
\hline & $>=30$ & $21,44 \pm 13,86$ & & $2835,56 \pm 702,21$ & \\
\hline \multirow[t]{2}{*}{ Education } & Less than high school & $19,58 \pm 10,25$ & \multirow[t]{2}{*}{0.606} & $2709,22 \pm 611,89$ & \multirow[t]{2}{*}{0.104} \\
\hline & high school or more & $22,20 \pm 15,19$ & & $3016,15 \pm 579,09$ & \\
\hline \multirow[t]{3}{*}{ Pre-pregnancy BMI } & Underweight & $20,84 \pm 16,27$ & \multirow[t]{3}{*}{0.763} & $2704,69 \pm 552,71$ & \multirow[t]{3}{*}{0.296} \\
\hline & Normal & $21,16 \pm 13,84$ & & $2802,14 \pm 506,33$ & \\
\hline & Overweight & $20,61 \pm 09,87$ & & $2981,20 \pm 679,89$ & \\
\hline \multirow[t]{2}{*}{ Parity } & Primiparous & $21,29 \pm 18,06$ & \multirow[t]{2}{*}{0.086} & $2773,75 \pm 569,85$ & \multirow[t]{2}{*}{0.432} \\
\hline & Multiparous & $20,20 \pm 08,46$ & & $2885,26 \pm 636,91$ & \\
\hline \multirow[t]{2}{*}{ Residence } & Urban & $22,50 \pm 15,19$ & \multirow[t]{2}{*}{0.395} & $2998,48 \pm 589,52$ & \multirow[t]{2}{*}{0.150} \\
\hline & rural & $19,69 \pm 10,97$ & & $2747,14 \pm 614,04$ & \\
\hline \multirow[t]{2}{*}{ Use of kohl } & yes & $30,45 \pm 21,34$ & \multirow[t]{2}{*}{0,001} & $3180,00 \pm 459,36$ & \multirow[t]{2}{*}{0.020} \\
\hline & No & $17,73 \pm 06,35$ & & $2750,56 \pm 620,66$ & \\
\hline \multirow[t]{2}{*}{ Occupational status } & Employed & $22,50 \pm 12,77$ & \multirow[t]{2}{*}{0.603} & $2491,25 \pm 813,64$ & \multirow[t]{2}{*}{0.103} \\
\hline & Un-employed & $20,53 \pm 12,88$ & & $2903,70 \pm 563,06$ & \\
\hline
\end{tabular}


Table 4: association between maternal BLL and the daily kohl use.

\begin{tabular}{|l|l|l|l|l|l|l|}
\hline \multirow{2}{*}{ variable } & \multicolumn{2}{|l|}{ Total population (n=58) } & \multicolumn{2}{l|}{ Cases LBW (n=29) } & \multicolumn{2}{l|}{ Controls NBW (n=29) } \\
\cline { 2 - 7 } & $\begin{array}{l}\text { Correlation } \\
\text { Coefficient }\end{array}$ & Sig & $\begin{array}{l}\text { Correlation } \\
\text { Coefficient }\end{array}$ & Sig & $\begin{array}{l}\text { Correlation } \\
\text { Coefficient }\end{array}$ & Sig \\
\hline Daily kohl use & $-0,429$ & 0,001 & $-0,207$ & 0,281 & $-0,453$ & 0,014 \\
\hline Daily kohl use a & $-0,429$ & 0,002 &,- 069 &, 761 &,- 469 &, 024 \\
\hline
\end{tabular}

apartial correlation by eliminating effect of: maternal age, parity, BMI, mothers occupation and education statue.

\section{DISCUSSION}

This study gives proof to adverse effects of maternal BLL on pregnancy outcomes. The principal purpose of our study is to establishthe stated research hypothesis, that the low birth weightis adversely influencedby exposure to low lead concentrations.

In this case-control study, 58 delivered women and their newborns were examined.the blood lead levels reported in other studies $[2,8,10,12,13]$ hadatendency to be higher than that in our investigation (mean 20,581 $\pm 12,476 \mathrm{ug} / \mathrm{l}$ ).

Although lead is one of the most poisonousstudied metals for the fetus during pregnancy, no significant associationwas found with low birth weight and maternal blood lead levels in this study.Mean of lead concentration in controls group was higher than in cases group but the difference was not statistically significant.Furthermore, no significant association was found between level of $\mathrm{Pb}$ in maternal blood and the studied pregnancy outcomes (head circumference, gestational age, sex and Apgar score).

In this regard, Iranpour et al. found similar result. The comparison of maternal BLL between 32 newborn with intrauterine growth retardation (IUGR) and 34 normal newborns reported that maternal BLL of healthy neonateswas higher than that of IUGR neonates; though, this difference was not significant.Nevertheless, maternal BLL was not related with LBW[14]. Other currents studiesalso reporting no effects of lead exposure on pregnancy outcomes.

Additionally, Mirghanitested the association between lead exposure and pregnancy outcomes, as well as gestational age, premature rupture of membranes, and even weight at birth, and found no significant relationship between exposure to lead and these pregnancy outcomes [6].

In another study performed at Al-Kharj hospital of Saudi Arabia during 2005 - 2006, the levels of three toxic metals (lead, cadmium, and mercury) were measured in maternal blood, and their effects on birth weight andsmall for gestational age (SGA), were assessed. As showed the result, lead, unlike other heavy metals has no impacts on the weight and SGA of newborns [15].

In a study carried out in Kuwait, Abdur Rahman et al. investigated the incidence of high BLL in pregnant women and its effect on birth weight, head circumference, Apgar score, gestational age, and other newborn characteristics. Results show no significant relationship between maternal BLL and any of the outcome variables tested [16].From study in 1986relating maternal and cord blood $\mathrm{Pb}$ levels with measures of size and Apgar scores, the analysis did not approach statistical significance [17]. In a cross sectional study, a total of 70 pregnant women and their newborns were selected at Mousavi Hospital of Zanjan, Iran, suggest that lead levels was not related with gestational age, height, or head circumference [8].
In contrast, several studies have suggested that prenatal low lead levels exposure is a negative predictor of pregnancy outcomes.Xie et al Detected decreasing birthweight across quartiles of maternal lead, with an adjusted difference of -47 grams $(95 \% \mathrm{CI}:-128,35)$ in the highest vs. lowest quartile [10]. Other Study sought to evaluate the relationship between toxic metals, nutrient combinations and birthweight among 275 mother-child pairs found that prenatal blood $\mathrm{Pb}$ was associated with lower Birthweight. Essentials elements $\mathrm{Fe}, \mathrm{Se}, \mathrm{Ca}$ and folate did not modify these relations[18].Taylor et al., examinedBlood samples of pregnant women derived from theAvon Longitudinal Study of Parents and Children (ALSPAC) and suggest that an increase of $1 \mu \mathrm{g} / \mathrm{dl}$ was associated with changes in birth weight of $-9.93 \mathrm{~g}$, head circumference $-0.03 \mathrm{~cm}$ and crownheel length $-0.05 \mathrm{~cm}$ [19].

Few data are available on the sex differences in the association between lead prenatal exposure and pregnancy outcomes. Findings of study done in Shanghai between September 2008 and October 2009 suggest that prenatal lead exposure may have sex-specific effects on birth outcomes. furthermore, a significant inverse association was found between cord BLL and head circumference only in the male group, and the decrease of ponderal index was significantly with increasing cord BLL only in females[20].

Concerning sources of lead, previous research focused on high dose lead exposure of women in the workplace such as smelters, lead battery plants and printing factories. Much less work concentrated on studying the effect of low dose sources of lead such as from food, air, soil, house dust and cosmetics.

In this item,contamination generally is greater in urban than rural areas where there is no specific or identified point sources, though, our finding showed that no differences in blood lead levels are observed between urban and rural maternal residence. A detailed research[21] confirm our result and suggest that rural populationsare at as great of risk of elevated blood lead levels as are urban populations.

Many studies have reported the chemical content of kohl and surma, particular Pb contents and as known the entry of this metal into the body is typically by ingestion or inhalation of particulates, though exposure through the skin or eye is possible [22,23]. Our findings suggest that frequency use of kohl during pregnancy was correlated with maternal BLL, but this relationship persist only in controls group that may beexplain elevate lead concentration in mothers in controls and not in cases. Naveed Zafar Janjua found that mothers who used surma (an eye cosmetic) daily had higher cord BLL (11.5 ug/dl) as compared to those who used it less frequently $(9.4 \mu \mathrm{g} / \mathrm{dl})[24]$.

\section{CONCLUSION}

from the small group of women participated in the present study it can be decided that prenatal lead does not have significant effect on newborn characteristics (sex, weight, 
age at birth and Apgar) and is unlikely to increase the risk of low birth weight. We found association between maternal frequency uses of kohl and lead levels, this finding add to proof from past investigations proposing that maternal low lead exposures might be related with cosmetics product and encourage the use of lead-free kohl in order to reduce sources of lead exposure with the end goal to protect fetal health.

\section{What is already known on this topic?}

Lead in maternal blood can be transmitted to the fetusthrough the placenta from 12 weeks of gestation until birth.

Lead is a toxic heavy metal associated with adverse pregnancy outcomes.

Maternal blood lead concentrations that do not produce clinical toxicity on pregnant women have been linked to adverse offspring.

\section{What this study adds}

The present study suggest that prenatal low lead exposure was not associated with low birth weight infant.

There was interaction of daily kohl (cosmetic product) use and maternal lead levels.

\section{Competing of interest}

Authors declared they have no competing of interest.

\section{Author's contributions}

Moussaoui F: data collection, management, statistics analysis, and manuscript writing. DEMMOUCHE Abbassia designed and supervised the study. Collection, analysis and interpretation of data were done by DEMMOUCHE Abbassia

\section{REFERENCES}

1. Azhar BS, Islam KS, Ferdouse A, Afrin S. Maternal Obstetric and Morbidity Factors in Relation to Infant Birth Weight. 2014;9.

2. Rodosthenous RS, Burris HH, Svensson K, Amarasiriwardena CJ, Cantoral A, Schnaas L, et al. Prenatal lead exposure and fetal growth: Smaller infants have heightened susceptibility. Environment International. 2017; 99:228-233.

3. Jelliffe-Pawlowski LL, Miles SQ, Courtney JG, Materna B, Charlton V. Effect of magnitude and timing of maternal pregnancy blood lead $(\mathrm{Pb})$ levels on birth outcomes. Journal of Perinatology. 2006; 26(3):154-162.

4. Taylor C, Golding J, Emond A. Adverse effects of maternal lead levels on birth outcomes in the ALSPAC study: a prospective birth cohort study. BJOG: An International Journal of Obstetrics \& Gynaecology. 2015; 122(3):322-328.

5. Chełchowska M, Jabłonka-Salach K, Ambroszkiewicz J, Maciejewski T, Gajewska J, Bulska E, et al. [Effect of cigarette smoking on blood lead levels in pregnant women]. Med Wieku Rozwoj. 2012; 16(3):196-204.

6. Mirghani Z. Effect of low lead exposure on gestational age, birth weight and premature rupture of the membrane. J Pak Med Assoc. 2010; 60(12):4.

7. Klein M, Kaminsky P, Barbé F, Duc M. [Lead poisoning in pregnancy]. Presse Med. 1994; 23(12):576-580.

8. Torabi Z, Halvachi M, Mohseni M, Khederlou H. The Relationship between Maternal and Neonatal Umbilical Cord Blood Lead Levels and their Correlation with Neonatal Anthropometric Indices. Journal of Comprehensive Pediatrics. 2018; 9(1).
9. Ahamed M, Mehrotra PK, Kumar P, Siddiqui MKJ. Placental lead-induced oxidative stress and preterm delivery. Environmental Toxicology and Pharmacology. 2009; 27(1):70-74.

10. Xie X, Ding G, Cui C, Chen L, Gao Y, Zhou Y, et al. The effects of low-level prenatal lead exposure on birth outcomes. Environmental Pollution. 2013; 175:30-34.

11. Zhu M, Fitzgerald EF, Gelberg KH, Lin S, Druschel CM. Maternal Low-Level Lead Exposure and Fetal Growth. Environmental Health Perspectives. 2010; 118(10):1471-1475.

12. Dwivedi D, Jain M, Jain S. An association between maternal lead and cadmium levels and birth weight of the babies in North Indian population. Open Journal of Obstetrics and Gynecology. 2013; 03(03):331-336.

13. Gundacker C, Fröhlich S, Graf-Rohrmeister K, Eibenberger B, Jessenig V, Gicic D, et al. Perinatal lead and mercury exposure in Austria. Science of The Total Environment. 2010; 408(23):5744-5749.

14. Iranpour R, Besharati AA, Nasseri F, Hashemipour M, BalaliMood M, Kelishadi R. Comparison of blood lead levels of mothers and cord blood in intrauterine growth retarded neonates and normal term neonates. Saudi Med J. 2007; 28(6):877-880.

15. Al-Saleh I, Shinwari N, Mashhour A, Rabah A. Birth outcome measures and maternal exposure to heavy metals (lead, cadmium and mercury) in Saudi Arabian population. International Journal of Hygiene and Environmental Health. 2014; 217(2-3):205-218.

16. Rahman A, Al-Rashidi HAG, Khan A-R. Association of Maternal Blood Lead Level During Pregnancy with Child Blood Lead Level and Pregnancy Outcome in Kuwait. Ecology of Food and Nutrition. 2012; 51(1):40-57.

17. Ernhart CB, Wolf AW, Kennard MJ, Erhard P, Filipovich HF, Sokol RJ. Intrauterine Exposure to Low Levels of Lead: The Status of the Neonate. Archives of Environmental Health: An International Journal. 1986; 41(5):287-291.

18. Luo Y, McCullough LE, Tzeng J-Y, Darrah T, Vengosh A, Maguire $\mathrm{RL}$, et al. Maternal blood cadmium, lead and arsenic levels, nutrient combinations, and offspring birthweight. BMC Public Health. 2017; 17(1).

19. Taylor CM, Tilling K, Golding J, Emond AM. Low level lead exposure and pregnancy outcomes in an observational birth cohort study: dose-response relationships. BMC Research Notes. 2016; 9(1).

20. Wang J, Gao Z-Y, Yan J, Ying X-L, Tong S-L, Yan C-H. Sex differences in the effects of prenatal lead exposure on birth outcomes. Environmental Pollution. 2017; 225:193-200.

21. Carrel M, Zahrieh D, Young SG, Oleson J, Ryckman KK, Wels B, et al. High prevalence of elevated blood lead levels in both rural and urban Iowa newborns: Spatial patterns and arealevel covariates. PLOS ONE. 2017; 12(5):e0177930.

22. Tiffany-Castiglioni E, Barhoumi R, Mouneimne Y. Kohl and surma eye cosmetics as significant sources of lead $(\mathrm{Pb})$ exposure. Journal of Local and Global Health Science. 2012; (2012):1.

23. Al-Ashban R., Aslam M, Shah A. Kohl (surma): a toxic traditional eye cosmetic study in Saudi Arabia. Public Health. 2004; 118(4):292-298.

24. Janjua NZ, Delzell E, Larson RR, Meleth S, Kabagambe EK, Kristensen S, et al. Maternal nutritional status during pregnancy and surma use determine cord lead levels in Karachi, Pakistan. Environmental Research. 2008; 108(1):6979. 